\title{
Daniel TOLLET (éd.), Études sur les terres saintes et les pèlerinages dans les religions monothéistes
}

Paris, Éditions Honoré Champion, coll. «Bibliothèque des religions du monde ", 2012, 269 p.

Bertrand Marceau

\section{(2) OpenEdition}

1 Journals

\section{Édition électronique}

URL : https://journals.openedition.org/assr/45245

DOI : $10.4000 /$ assr.45245

ISSN : $1777-5825$

Éditeur

Éditions de l'EHESS

\section{Édition imprimée}

Date de publication : 1 décembre 2018

Pagination : $378-380$

ISSN : 0335-5985

\section{Référence électronique}

Bertrand Marceau, «Daniel tolıet (éd.), Études sur les terres saintes et les pèlerinages dans les religions monothéistes », Archives de sciences sociales des religions [En ligne], 184 | octobre-décembre 2018, mis en ligne le 01 décembre 2018, consulté le 17 janvier 2022. URL : http://

journals.openedition.org/assr/45245; DOI : https://doi.org/10.4000/assr.45245

Ce document a été généré automatiquement le 17 janvier 2022.

(C) Archives de sciences sociales des religions 


\section{Daniel TOLLET (éd.), Études sur les terres saintes et les pèlerinages dans les religions monothéistes}

Paris, Éditions Honoré Champion, coll. « Bibliothèque des religions du monde ", 2012, 269 p.

\section{Bertrand Marceau}

\section{RÉFÉRENCE}

Daniel TOLLET (éd.), Études sur les terres saintes et les pèlerinages dans les religions monothéistes, Paris, Éditions Honoré Champion, coll. «Bibliothèque des religions du monde », 2012, $269 \mathrm{p}$.

1 Formé de quatorze contributions rassemblées par Daniel Tollet, ce volume d'une lecture aisée et à l'appareil critique diversement développé aborde le problème des voyages et des pèlerinages dans les terres saintes dans un large espace (Europe continentale, pourtour méditerranéen et Proche-Orient) et sur le temps long (de l'Antiquité au $\mathrm{xx}^{\mathrm{e}}$ siècle), dans le cadre des religions monothéistes et principalement du christianisme. Chaque contribution est celle d'un spécialiste ayant souvent développé ailleurs plus amplement les thèmes de son objet, permettant des comparaisons fructueuses et sans lourdeur. En partant de la définition générale d'Alphonse Dupront, selon lequel le pèlerinage est « une expérience singulière de vie religieuse collective ou individuelle, dans une quête tendue de sacralisation qui doit, à quelque degré que ce soit, prendre des aspects volontaristes, mieux encore d'héroïcité » (p. 48), il y a place pour un large débat historique et épistémologique, incluant les différentes approches anthropologiques, depuis les théories fonctionnalistes sur le pèlerinage comme facteur structurant de l'identité sociale, jusqu'au pèlerinage comme champ de conflits entre différents discours cherchant à créer, par exemple, un espace religieux homogène (J. Eade et M. Sallnow), comme au temps de l'impérialisme chrétien de Théodose $\mathrm{I}^{\mathrm{er}}$, 
selon le «pèlerinage textuel» d'Égérie jusqu'à Jérusalem (Pierluigi Lanfranchi, "Remarques sur la sacralisation de l'espace dans l'Itinéraire d'Égérie », p. 45-54).

2 Les Lieux Saints et Jérusalem se trouvent en effet marqués par "une forte charge poétique, émotionnelle et religieuse» (Mireille Hadas-Lebel, "Le pèlerinage à Jérusalem dans l'Antiquité », p. 17) qui produit ses effets sur la longue durée (et encore à l'époque contemporaine), effets puissamment contradictoires : il n'est que de voir les débats intenses et les polémiques incessantes touchant la question de la réfection matérielle du Saint-Sépulcre dans les années 1930, au temps du mandat anglais sur la Palestine et depuis, notamment entre les six principales communautés (dont les Arméniens apostoliques, les Grecs apostoliques et les catholiques latins) en charge de la garde des lieux depuis le code intitulé Statu quo réglé par les Turcs en 1852: entre autres divisions, ces communautés craignaient une possible immixtion de l'Église anglicane (Agathe Mayeres-Rebernik, «Le Saint-Sépulcre durant l'Entre-deux-guerres : démêlés concernant sa restauration", p. 177-198). La confusion entre droits de possession et droits d'usage, la nécessité de l'ouverture aux fidèles externes au sanctuaire, les profondes divergences juridico-théologiques, ainsi que l'héritage de traditions controversées ou partiellement reconstruites, forment autant de nœuds séculaires d'affrontements, y compris dans la question, cruciale pour la perpétuité matérielle du lieu, de la reconstruction de la basilique. Étaient en effet au minimum nécessaires des restaurations architecturales d'ampleur à apporter aux bâtiments usés par les siècles, les secousses sismiques, les incendies et les pillages, le tout au milieu des donations pieuses ou charitables constituées par les waqf musulmans entourant le Saint-Sépulcre. Peu d'accommodements se firent jour avant l'accord de 1954 entre la Custodie de Terre Sainte, le Patriarcat grec-orthodoxe et le Patriarcat arménien, prélude à certaines restaurations indispensables dans la seconde moitié $\mathrm{du} \mathrm{xx}^{\mathrm{e}}$ siècle.

3 Autour des grands sanctuaires et notamment de la Terre Sainte, la concurrence politico-religieuse est d'autant plus forte que, en dépit des contextes historiques, le nombre des pèlerinages reprend périodiquement de la vigueur sous de nouvelles formes, comme le pèlerinage collectif au $\mathrm{xIx}^{\mathrm{e}}$ siècle (Catherine Nicault, «Les pèlerinages français en Terre Sainte au XIX siècle », p. 163-176). À compter de 1853 pour la Société de Saint-Vincent-de-Paul ou de 1882 pour les Assomptionnistes français, et après des pèlerinages d'abord nationaux (Ars, Lourdes ou Paray-le-Monial) ou européens (Rome), la promotion du pèlerinage oriental accompagne le «néocatholicisme » (R. Rémond) ou le «populisme chrétien » (M. Lagrée), développant par exemple la littérature de pèlerinage. On relèvera ici que bien souvent il ne s'agit pas d'initiatives centralisées, depuis Rome par exemple, organisant les pèlerinages comme les missions d'évangélisation le furent à partir de la fondation de la Propaganda Fide (1622). Au contraire, les contributions rassemblées par Daniel Tollet, qui étudie ici « Le pèlerinage de Mikołaj-Krzystof Radziwiłł en Terre sainte (1582-1584)» (p. 117-129), premier magnat lituanien converti au catholicisme, fourmillent d'éléments attestant la multiplicité des acteurs locaux en butte aux autorités centrales. Le développement d'un pèlerinage accompagne souvent la notion de "terre sainte", à l'instar de l'Espagne embellie par la présence du corps de l'apôtre Jacques en Galice. Dans le cas de Compostelle en effet, où la foi et le nombre des pèlerins ont précédé au début $d u \mathrm{IX}^{\mathrm{e}}$ siècle les encadrements politiques postérieurs, la fin du califat de Cordoue pousse les rois chrétiens à créer un réseau urbain et villageois attirant des immigrants français, germaniques ou flamands, et à former autour du sanctuaire galicien un rayonnement 
d'origine apostolique augmenté de la gloire de la redécouverte prétendue par l'empereur Charlemagne suite à une apparition: mais cette politique du pèlerinage amène de fortes tensions avec Rome notamment, la papauté excommuniant par exemple au $\mathrm{XI}^{\mathrm{e}}$ siècle l'évêque Cresconius pour sa revendication de l'origine apostolique de son siège épiscopal (Adeline Rucquoi, «Saint-Jacques de Compostelle : un pèlerinage et ses textes ", p. 77-92).

4 Fait socio-religieux global, les pèlerinages et la vénération des saints sont marqués par les conditions politiques et sont rendus possibles par de solides structures financières, dans le cas fréquent de contributions régulières versées par des États ou des Églises, aussi bien que de versements plus irréguliers provenant des fidèles. En ce sens les strates sociales de la vénération peuvent être très marquées, par exemple dans le cas du culte des saints au Maghreb, où le rituel du Stambâli est pratiqué par les couches économiquement inférieures de la population (Saloua Ghrissa, «Le culte des saints en Tunisie: croyances populaires et pratiques religieuses », p. 231-247). Dans le cas de " Lorette, refuge des catholiques persécutés, $\mathrm{XVI}^{\mathrm{e}}-\mathrm{XVII}{ }^{\mathrm{e}}$ siècles » (p. 133-139), Yves-Marie Bercé met en exergue les fondements géopolitiques et sociaux (et non seulement religieux) du "plus grand pèlerinage du monde catholique " (p.134) à l'époque moderne. Supposée avoir été la chambre de la Vierge à Nazareth, la Sainte Maison ou Santa Casa des Marches est un pôle d'attraction pour les catholiques français (à l'instar de Montaigne) au temps des guerres de Religion, pour les prêtres irlandais au temps des persécutions de la reine Élisabeth, pour les pêcheurs italiens enlevés ou menacés d'enlèvement par les pirates turcs dans l'Adriatique, ou pour les Illyriens ou Esclavons sous domination vénitienne de Raguse (Dubrovnik) ou de Spalato (Split). En effet, le sanctuaire marial a recueilli «toutes les causes des communautés catholiques en lutte dans leurs différents pays » (p. 139). Du côté protestant, si le rejet luthérien des œuvres conduit à la fin des pèlerinages, cela n'empêche pas la naissance de la littérature de voyage, non encore codifiée, dans les lieux saints. C'est ainsi que les relations de Leonhard Rauwolf ou de Salomon Schweigger étudiées par Colette Gauthier (« Voyages en Terre Sainte par des Allemands luthériens à la fin du XvI siècle», p. 107-116) signalent les renseignements sur les voyages en commun de protestants et de catholiques (même si ces derniers ne sont pas nommés comme tels dans les sources de voyageurs protestants), sur la piété et les dévotions des Turcs, ou sur les divisions religieuses que cela traduit en creux dans le monde occidental. En ce sens, le sujet du volume incite fructueusement au repérage des différentes influences créées à l'occasion des nombreuses circulations pèlerines, par exemple avec les liens entre mystique juive et mystique musulmane (notamment soufie) autour du développement de la visitation des tombes palestiniennes (Paul B. Fenton, « Influences soufies sur le développement de la Qabbale à Safed : le cas de la visitation des tombeaux », p. 201-230).

Certes, tous les sanctuaires et tous les voyages ne sont pas étudiés ni même mentionnés dans ce volume, et la comparaison avec d'autres sanctuaires (comme Lalibela, la Jérusalem éthiopienne aux églises monolithiques, à partir de la fermeture des Lieux Saints et reproduisant leur géographie) ou avec d'autres sources (comme le récit fameux de Greffin Affagart publié jadis par J. Chavanon sous le titre de Relation de Terre Sainte (1533-1534), Paris, 1902) aurait pu apporter des éclairages précieux. Mais c'est là mince regret, avec les quelques coquilles (Flavius Joseph pour Flavius Josèphe p. 122, ou mer adriatique pour mer Adriatique p. 133) et erreurs (ce sont les Franciscains et non les Bernardins qui ont la garde des Lieux Saints, p. 123), devant l'abondant matériau 
diachronique rassemblé ici, le principal avantage de ce volume étant de contribuer au décloisonnement chronologique et spatial des études sur les voyages et sur les pèlerinages, décloisonnement finalement peu fréquent. 